\title{
Interior crack initiation during the very-high-cycle fatigue of railway wheel steel under axial loading and rolling contact loading
}

\author{
Xiao-Long $\mathrm{Liu}^{1}$, Pengcheng $\mathrm{Gao}^{1}, \mathrm{Si} \mathrm{Wu}^{2}$, Guanzhen $\mathrm{Zhang}^{2}$, and Tao Cong ${ }^{2}$ \\ ${ }^{1}$ Beijing Jiaotong University School of Electronic and Information Engineering \\ ${ }^{2}$ China Academy of Railway Sciences Corporation Limited
}

November 30, 2021

\begin{abstract}
In this paper, a comparative study of the very-high-cycle fatigue (VHCF) behavior of railway wheel steel under axial loading and rolling contact loading was conducted. Fatigue tests were performed with an ultrasonic fatigue test machine under axial loading, and the fracture surfaces from the fatigue tests and shattered rims taken from the failed railway wheels were observed. The wheel steel under axial loading presents a VHCF behavior with Mode I crack, and that under rolling contact loading is a VHCF behavior with mix Mode II-III crack. For the VHCF behavior with Mode I crack ,surface and interior crack initiation occurred with equal probability at both low and high stress levels and produced a dual linear S-N curve since the value of fatigue limits for the surface and interior crack initiation are close. For the VHCF behavior with mix Mode II-III crack, cracks were initiated from the interior $\mathrm{Al}_{2} \mathrm{O}_{3}$ inclusion and the fatigue life was beyond $10^{7}$ cycles. Fatigue bands were observed on the fracture surface under rolling contact loading. The ferrite nanograins formed due to the stress state of shear plastic strain with a large compressive stress. The formed nanograins were softer than the matrix caused by the redistribution of the carbon.
\end{abstract}

Interior crack initiation during the very-high-cycle fatigue of railway wheel steel under axial loading and rolling contact loading

Xiaolong $\mathrm{Liu}^{1}$, Pengcheng $\mathrm{Gao}^{1}$, Si Wu ${ }^{2}$, Guanzhen Zhang ${ }^{2}$, Tao Cong ${ }^{1,2}, 11^{*}$ Corresponding author. Tel./fax: +86 10 51683300. E-mail address: 18610453070@163.com (Tao Cong).

${ }^{1}$ School of Mechanical Electronic $\&$ Control Engineering, Beijing Jiaotong University, Beijing 100044, China

${ }^{23}$ Metals $\&$ Chemistry Research Institute, China Academy of Railway Sciences Corporation Limited, Beijing, 100081, China

Abstract:In this paper, a comparative study of the very-high-cycle fatigue (VHCF) behavior of railway wheel steel under axial loading and rolling contact loading was conducted. Fatigue tests were performed with an ultrasonic fatigue test machine under axial loading, and the fracture surfaces from the fatigue tests and shattered rims taken from the failed railway wheels were observed. The wheel steel under axial loading presents a VHCF behavior with Mode I crack, and that under rolling contact loading is a VHCF behavior with mix Mode II-III crack. For the VHCF behavior with Mode I crack, surface and interior crack initiation occurred with equal probability at both low and high stress levels and produced a dual linear S-N curve since the value of fatigue limits for the surface and interior crack initiation are close. For the VHCF behavior with mix Mode II-III crack, cracks were initiated from the interior $\mathrm{Al}_{2} \mathrm{O}_{3}$ inclusion and the fatigue life was beyond $10^{7}$ cycles. Fatigue bands were observed on the fracture surface under rolling contact loading. The ferrite nanograins formed due to the stress state of shear plastic strain with a large compressive stress. The formed nanograins were softer than the matrix caused by the redistribution of the carbon.

Keywords:Wheel steel; Very-high-cycle fatigue; Rolling contact loading; axial loading; Nanograins 


\section{Introduction}

The new research topic of very-high-cycle fatigue (VHCF) is drawing increased attention because many engineering components, such as high-speed railway wheels, turbine blades and automobile cylinders, require $10^{8}$ or even more loading cycles for safe performance $[1,2]$. With the increasing running speeds and axle loads in modern railways, a new challenge of shattered rims is posed to the wheel/rail pair [3, 4]. shattered rims is a form of rolling contact fatigue caused by subsurface and interior crack initiation [5-8]. In general, cracks of shattered rims initiated from the interior inclusion with a fatigue life more than $10^{7} \mathrm{cycles}$, indicating a typical VHCF under rolling contact loading $[9,10]$. Therefore, the investigation of VHCF under rolling contact loading and the comparison study with VHCF under axial loading are with science significance and engineering demanding.

High-strength steels and titanium alloys present VHCF behavior under axial loading, i.e., the cracks are initiated from interior nonmetallic inclusions and the fatigue life is beyond $10^{7}$ cycles. The whole region where crack initiation and early propagation occur exhibits a fish-eye (FiE) pattern, and a relatively rough morphology is often observed [11-16]. Moreover, nanograins are formed in the fine granular area (FGA) during VHCF crack initiation. Recent investigations based on fatigue tests at positive and negative stress ratios have revealed that a nanograin layer with a thickness of several hundred nanometers formed on both sides of the crack surface due to the numerous cyclic pressing (NCP) process between the originated crack surfaces at negative stress ratios $[17,18]$. However, the VHCF of wheel steel with a pearlite microstructure is rarely reported. This situation raises an interesting question: Does the wheel steel also present VHCF behavior under axial loading, and what are the corresponding VHCF features? As known, there are three types of cracks in the fracture mechanics (Mode I, II and III). The investigation of VHCF focused on the mode-I crack. The VHCF with mode II or III cracks are indeterminacy.

In general, the subsurface cracks during rolling contact fatigue of bearings are called "white etching cracks" or "butterfly cracks" [19-23]. The mechanism of butterfly cracks was proposed. First, the material in the vicinity of the cracks changes into the so-called white-etching region that is a consequence of severe localized mechanical mixing of the microstructural constituents [24]. Then, these butterfly cracks eventually link up into large networks that lead to failure $[25,26]$. This mechanism is referred to as "white structure flaking" $[27,28]$. It is worth noting that the white-etching matter (WEM) that causes the greatest damage is that which is harder than the surrounding matrix [29,30]. Grabulov et al [31,32] reported that butterfly cracks and nanocrystalline ferrite formed around nonmetallic inclusions during the VHCF of bearing steel under rolling contact loading. Shattered rims are caused by subsurface cracks in the wheel steels. However, the microstructure evolution in the fracture surface of shattered rims has never been investigated.

In this paper, a comparative study on the VHCF behavior of railway wheel steel under axial loading and rolling contact loading was conducted. First, fatigue tests were performed with an ultrasonic fatigue test machine under axial loading, and relevant S-N curves were obtained. Then, the fracture surfaces of the fatigue tests and shattered rims taken from the failed railway wheels were observed by scanning electron microscopy (SEM), which indicated a similar fractography of the VHCF samples under axial loading and rolling contact loading. Finally, focused ion beam (FIB) and transmission electron microscopy (TEM) were applied to characterize the microstructure on the fracture surface under axial loading and rolling contact loading. Nanograins formed on the whole fracture surface under rolling contact loading, while no nanograins were detected on the whole fracture surface under axial loading. Moreover, the formed nanograins were softer than the matrix, which was attributed to the redistribution of carbon.

\section{Materials and Experimental Procedures}

\subsection{Testing wheels and materials}

The material of the railway wheels was composed of a forged ER8 medium carbon steel. The chemical compositions (mass percentage) are: $0.56 \mathrm{C}, 0.40 \mathrm{Si}, 0.80 \mathrm{Mn}, 0.02 \mathrm{P}, 0.015 \mathrm{~S}, 0.30 \mathrm{Cu}, 030 \mathrm{Cr}$ and balance Fe. The material comprised pearlite and ferrite was shown in Fig. 1. In addition, the mechanical properties of the material were measured by tensile testing on an MTS 810 system. The diameter of the cylindrical 
specimen was $6 \mathrm{~mm}$ and the strain rate was $10^{-4} \mathrm{~s}^{-1}$. Five specimens were tested to obtain a yield strength of $673 \mathrm{MPa}$, tensile strength of $950 \mathrm{MPa}$ and uniform elongation of $11.5 \%$ for the material.

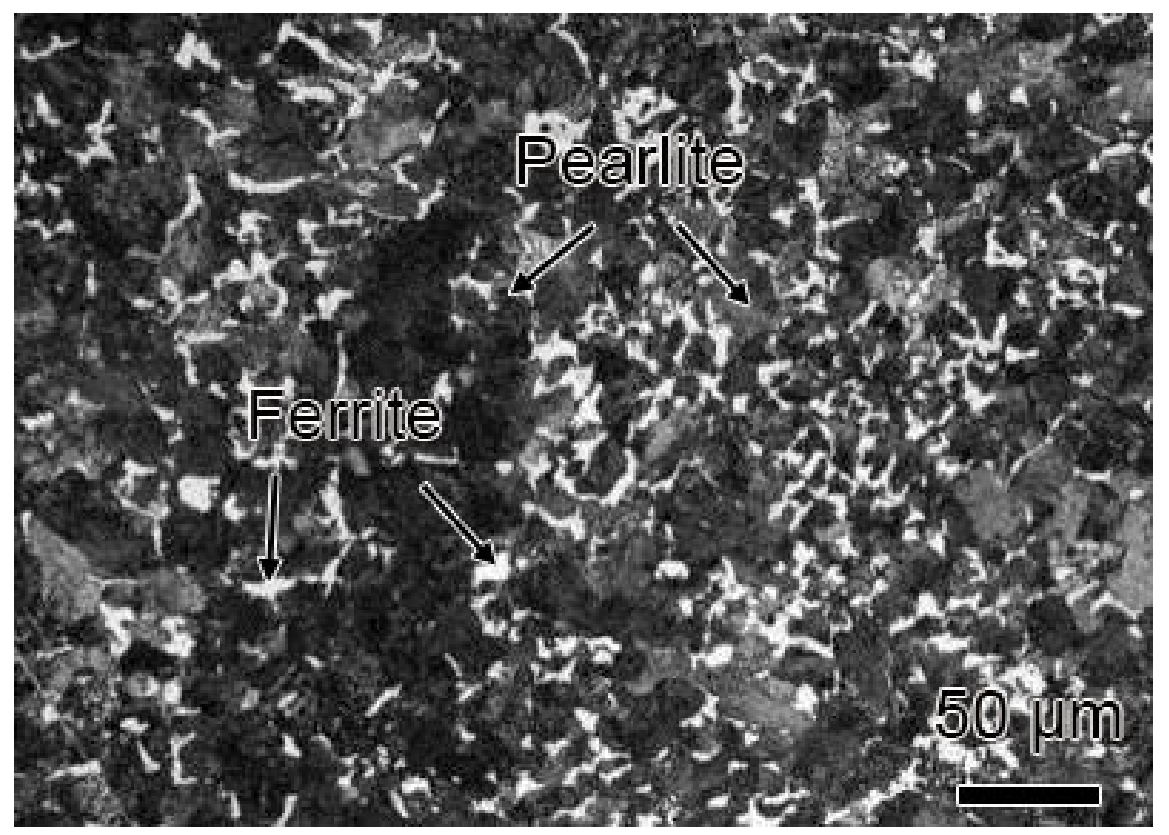

Fig. 1. Optical microscopy of the wheel steel .

\subsection{Fatigue testing methods}

Fatigue tests were performed using an ultrasonic fatigue testing machine (SHIMADZU USF-2000) at a frequency of $20 \mathrm{kHz}$ at room temperature. The resonance interval was $100 \mathrm{~ms}$ per $500 \mathrm{~ms}$ and the stress ratio was $R=-1$. Air cooling was used to cool the specimens during the ultrasonic fatigue test. Moreover, a removed wheel with a shattered rim from rail vehicles was shown in Fig.2. A interior crack was detected by ultrasonic detection during service. The crack in the shattered rim was extracted from the service wheel, and opened by an electric cutting saw to observe the crack surface. The fracture surfacesin the specimens and failed wheel was observed by an FEI Quanta 200 FEG field-emission scanning electron microscope, and the inclusions at the crack initiation region were analyzed by energy dispersive spectrometry (EDS). 


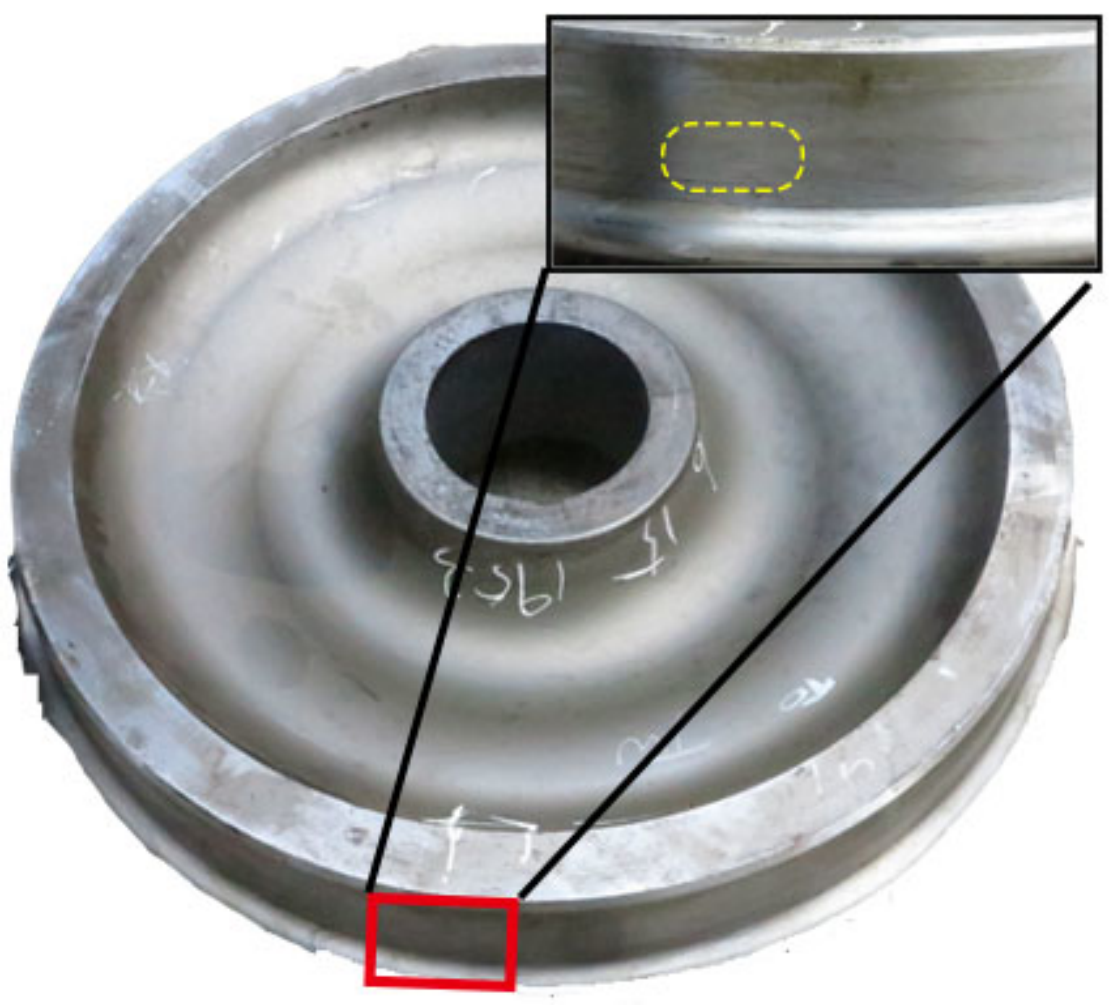

Fig. 2. Photographs taken from railway wheels with nonpenetrating shattered rims.

The microstructure on the fracture surface was characterized by transmission electron microscopy (TEM). First, TEM samples were prepared by a focused ion beam equipment (HELIOS NanoLab 600i). The voltage and current parameters during sample collection were $30 \mathrm{kV}$ and $2.5 \mathrm{nA}$, respectively, and those during sample thinning were $30 \mathrm{kV}$ and $0.79 \mathrm{nA}$, respectively. Then, samples were observed via a JEM-2100F transmission electron microscope with selected area electron diffraction (SAED) with a voltage of $200 \mathrm{kV}$, and the diameter of the diffraction area during SAED was $200 \mathrm{~nm}$. The SAED pattern comprising discontinuous diffraction rings suggests that several nanograins existed within the $200 \mathrm{~nm}$ diameter diffraction area. The SAED pattern of isolated spots indicated normal diffraction from a single grain. Nanoindentation was performed on the profile of the crack initiation region using a Hysitron TriboScope Nanomechanical Test Instrument to study the mechanical properties. A loading rate of $1 \mathrm{mN} / \mathrm{s}$ and a maximum load of $5 \mathrm{mN} / \mathrm{s}$ were chosen, with a $5 \mathrm{~s}$ dwell time at the level of maximum loading. Then, the chemical composition of different regions of the wheel steel was determined by electron probe microanalysis (EPMA, JXA-8230, $20 \mathrm{kV}$ ).

\section{Results and Discussion}

\section{1. $S$ - $N$ curves}

Fig. 3a presents the $\mathrm{S}-\mathrm{N}$ curve in terms of applied stress amplitude for the ER8 steel. The crack initiation site switched from the surface to the interior from a high cycle fatigue (HCF) to a VHCF behavior. The magnitudes of the test stress amplitude in $\mathrm{HCF}$ and VHCF were almost within the same range of 300-350 $\mathrm{MPa}$, which indicates a clear dual S-N curve. For a given amplitude stress within 300-350 MPa, the fatigue life of the surface crack initiation is around $10^{6}$ cycles while the fatigue life of the interior crack initiation is within $10^{7}-10^{8}$ cycles. It is interesting that the fatigue life ranges from $10^{6}$ to $10^{8}$ for the same stress amplitude. Here, we define two fatigue limit of the wheel steel, i.e., fatigue limit of surface and interior crack initiation. The fatigue limit of surface crack initiation is related to the formation of persistant slip band, and that of interior crack initiation is dominated by the inclusion size. Of cause the values of these two 
fatigue limits are varied. The fatigue life of interior cracks initiation is much larger than that of surface crack initiation. Then, three types of S-N curves were defined, i.e. the single linear (Type I), the dual linear (Type II), and stepwise (Type III), as shown in Fig. 3b. For the case in which the fatigue limit of interior crack initiation is larger than that of surface crack initiation, the S-N curve for surface crack initiation covered that of interior crack initiation and presents a single linear curve (Type I in Fig. 3b). For the case in which the fatigue limit of interior crack initiation is smaller than that of suface crack initiation, surface crack initiation occurred at high stress levels or during HCF and interior crack initiation at low stress levels or during VHCF; these trends can be observed for high-strength alloys [14,17], which present a typical stepwise $\mathrm{S}-\mathrm{N}$ curve (Type III in Fig. 3b). For the case where the fatigue limits of interior and surface crack initiation are close, surface and interior crack initiation occurred with equal probability at both low and high stress levels and produced a dual linear S-N curve (Type II in Fig. 3b). This is the reason for the dual linear S-N curve of the wheel steel.
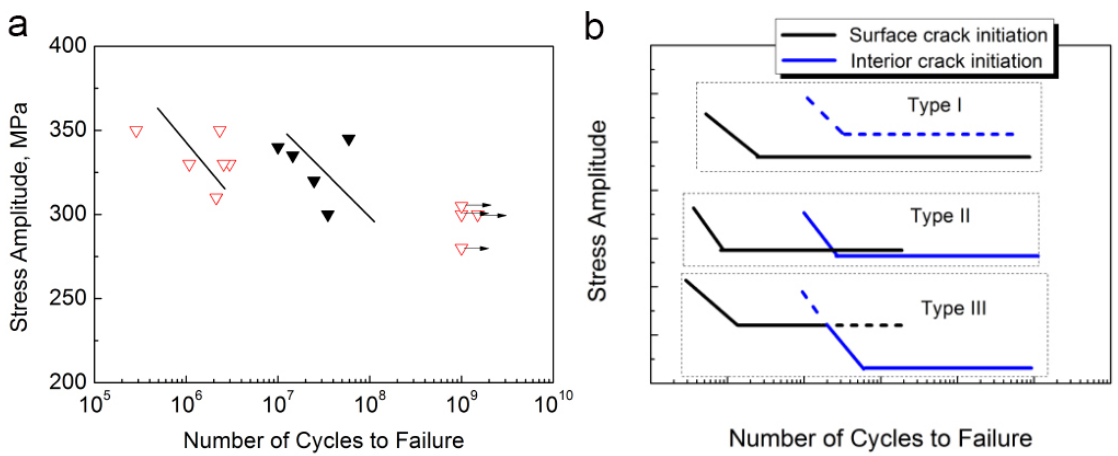

Fig. 3. (a) S-N curves in terms of applied stress amplitude for ER8; the open upside down triangles with arrows indicate run out, open upside down triangles indicate surface crack initiation, and solid upside down triangles indicate interior crack initiation. (b) Schematic presentation of the S-N curves.

Fig. 4a shows the depth of the crack initiation region from the tread versus the fatigue life for shattered rims from the statistical data over the last ten years. The fatigue life was independent of the depth of the crack initiation region. The depth of the crack initiation region from the tread was in the range from 10-25 $\mathrm{mm}$ for all the shattered rims. The wheels with shattered rims had a service from $10^{5}-10^{7} \mathrm{~km}$, and the corresponding fatigue life was within a range from $10^{7}-10^{9}$ cycles, which indicates VHCF behavior. The stress distribution for the VHCF under axial loading can be regarded as uniformly distributed axial stress. The stress distribution for the VHCF under rolling contact loading is a multiaxial stress consists of a pressure stress in the radial direction, a shear stress in axle direction and a shear stress in circumference direction. complicated. Fig. 4b presents the stress variation along the radial direction of the wheel. For the case of shattered rim (interior crack initiation) with the depth $10^{\sim} 25 \mathrm{~mm}$, the pressure stress is in the elastic stage, and no evident press between the crack surface was observed. Meanwhile, the two shear stresses are also in the low level. It is consistent with VHCF features of a relatively low cyclic stress below conventional fatigue limit and beyond $10^{7}$ fatigue cycles. 

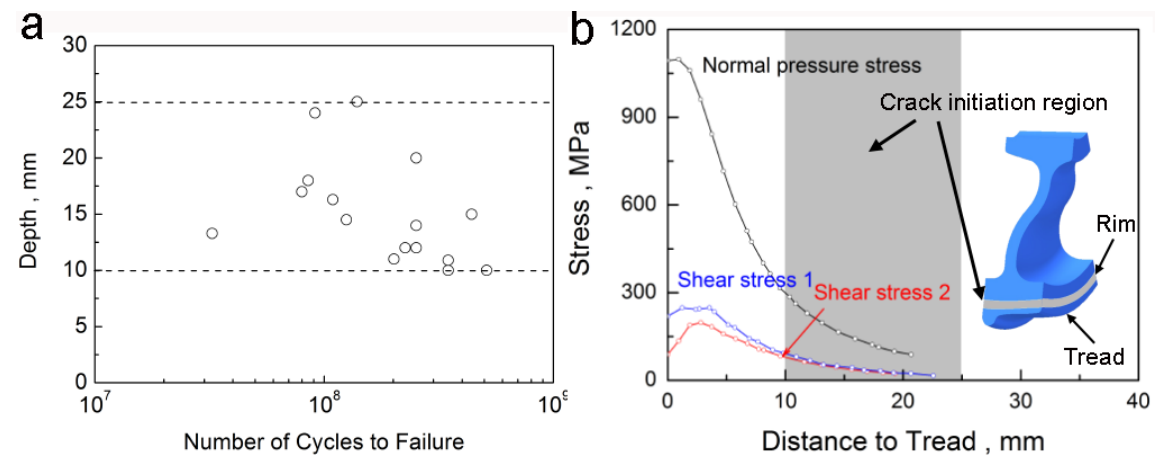

Fig. 4. (a) Depth of crack initiation region versus fatigue life for wheels in service, (b) stress distribution along the direction of wheel diameter, inset showing the crack initiation region in the wheel rim.

\subsection{Fractography and dimensions of inclusions and fish-eye}

Fig. 5 presents a typical fracture surface of the interior crack initiation region during VHCF under axial loading for the tested ER8 steel wheel. The whole region that underwent crack initiation and early propagation exhibited a pattern of fish-eye (FiE). The initiation regions at the inclusions (CaS by EDS) were located generally at the center of the FiE. A FGA was not observed around the inclusion. The average size of the inclusions was approximately $50 \mu \mathrm{m}$ and that of the FiE was approximately $200 \mu \mathrm{m}$. Inclusions served as crack origins during the VHCF of martensitic steel (such as high-strength steels), while that of pearlitic steel is rarely reported. The crack in axial loading is Mode-I crack. Then, the morphology in Fig. 5 is the VHCF features with Mode-I crack.
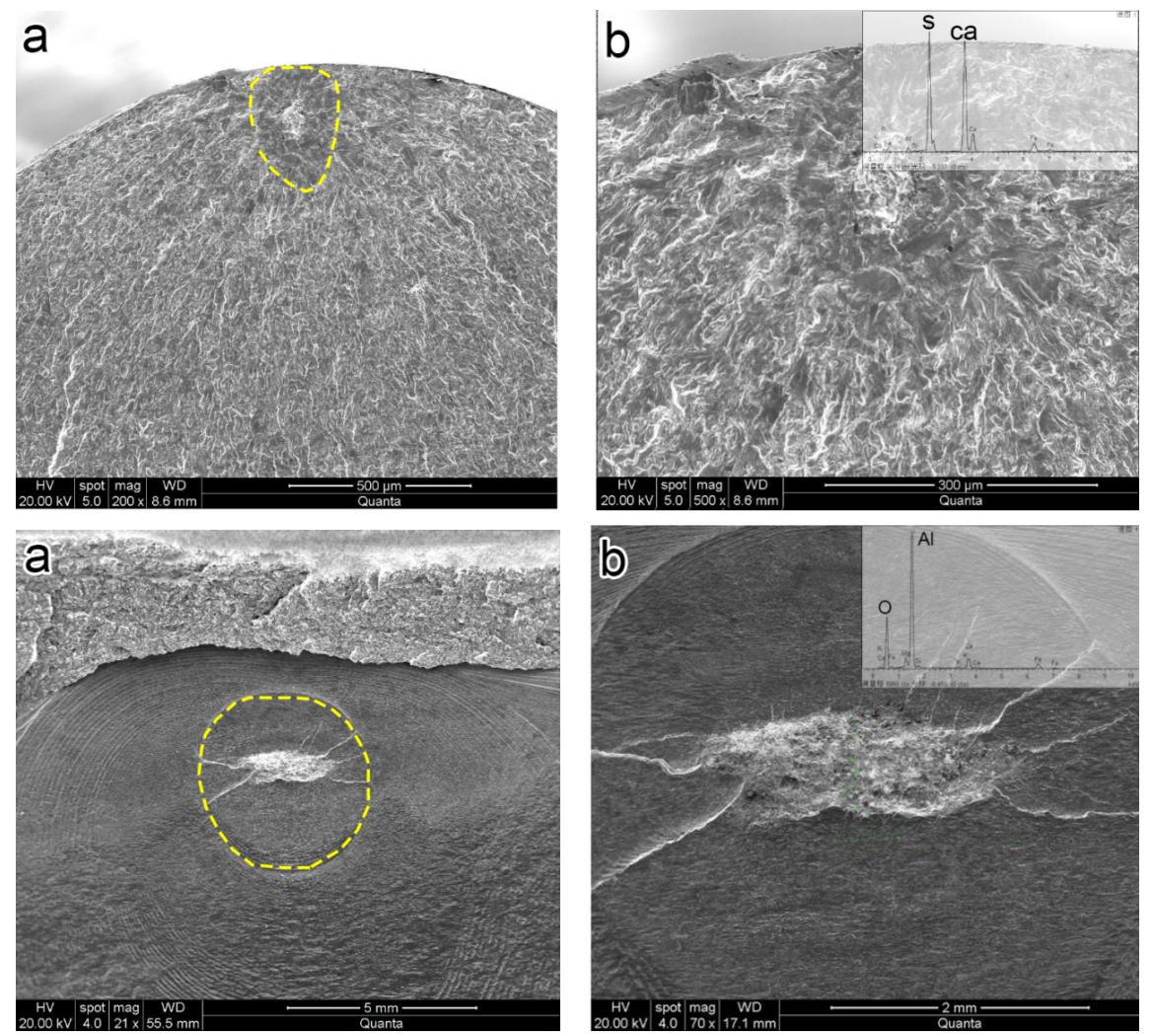
Fig. 5. Fracture surface of ER8, where $R=-1, \sigma_{\mathrm{a}}=300 \mathrm{MPa}$, and $N_{\mathrm{f}}=2.32 \times 10^{7}$ : (a) SEM image showing three regions of the inclusion, the FiE, and the FiE-Fracture, and (b) high-magnification SEM image showing the FiE region, where the inset shows the EDS results of the inclusion.

Fig. 6a presents the fracture surface of shattered rims under rolling contact loading, indicating three typical regions with different morphologies, i.e., the inclusion $\left(\mathrm{Al}_{2} \mathrm{O}_{3}\right.$ by EDS in Fig. 6b), FiE, and crack propagation regions with fatigue bands. The uniform equidistant distribution of fatigue bands in the propagation region is a unique feature of the VHCF under rolling contact loads, which indicated that the crack propagation rate was constant, as marked by the arrows in Fig. 6a. This feature differed from the rapid propagation for the case of uniaxial loading. Although FGAs were typical features in the crack initiation region for VHCF under uniaxial loading [17], FGAs were not observed around the inclusions for the case of rolling contact loading. For the shattered rims, a rolling contact loading was applied to the wheels, which is a multiaxial stress state as shown in Fig. 4b. Due to the large compressive stress on the contact surface that normally suppress any Mode I deformation of the crack, the crack propagated mainly in a mixed Mode II- III [6]. Therefore, the fracture surface of the shattered rim was the typical morphology for VHCF with a mixed Mode II- III crack.
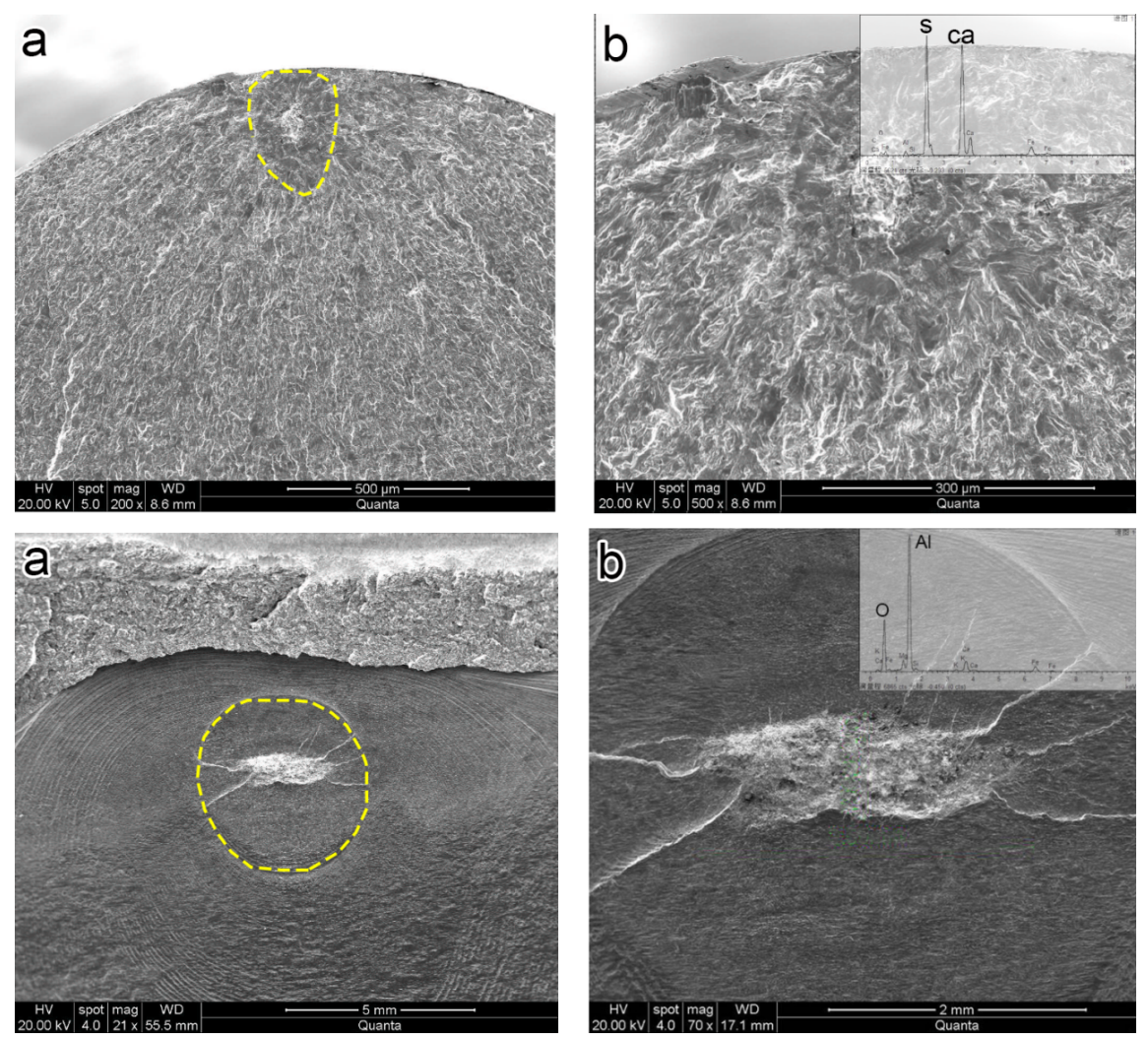

Fig. 6. Fracture surface of shattered rims under rolling contact loading, where $N_{\mathrm{f}}=3.38 \times 10^{8}$ : (a) SEM image showing three regions of the inclusion, FiE, and crack propagation region with beach marks, and (b) high-magnification SEM image showing the FiE region, where the inset shows the EDS results of the inclusion.

\subsection{Microstructure characterization for the cases under axial loading and rolling contact loading}

First, a comparative investigation was conducted on the microstructure changes at the crack initiation region during VHCF under axial loading and rolling contact loading, as shown in Figs. 7 and 8. Fig. 7 presents the TEM observations and SAED results on the sample cut from the crack initiation region for the case 
under axial loading. Fig. 7a is the SEM image that shows the FiE region (dotted curve loop) where an FIB sample near the inclusion was cut (marked by a rectangle in Fig. 7a). Then, the profile morphology of the FIB sample was carefully examined by TEM, and the image is shown in Fig. 7b, indicating only the original microstructure of pearlite. SAED examinations were conducted on the locations near and far away from the surface, and the results are shown in Figs. 7c and d, respectively. For both locations, the SAED patterns show isolated diffraction spots, which indicates normal diffraction from a single grain. A second TEM sample from the crack initiation region was cut by FIB. This sample was again examined by TEM and SAED, indicating the same microstructure features. Therefore, we can infer that no microstructure change occurred in the crack initiation region for the case of VHCF under axial loading.

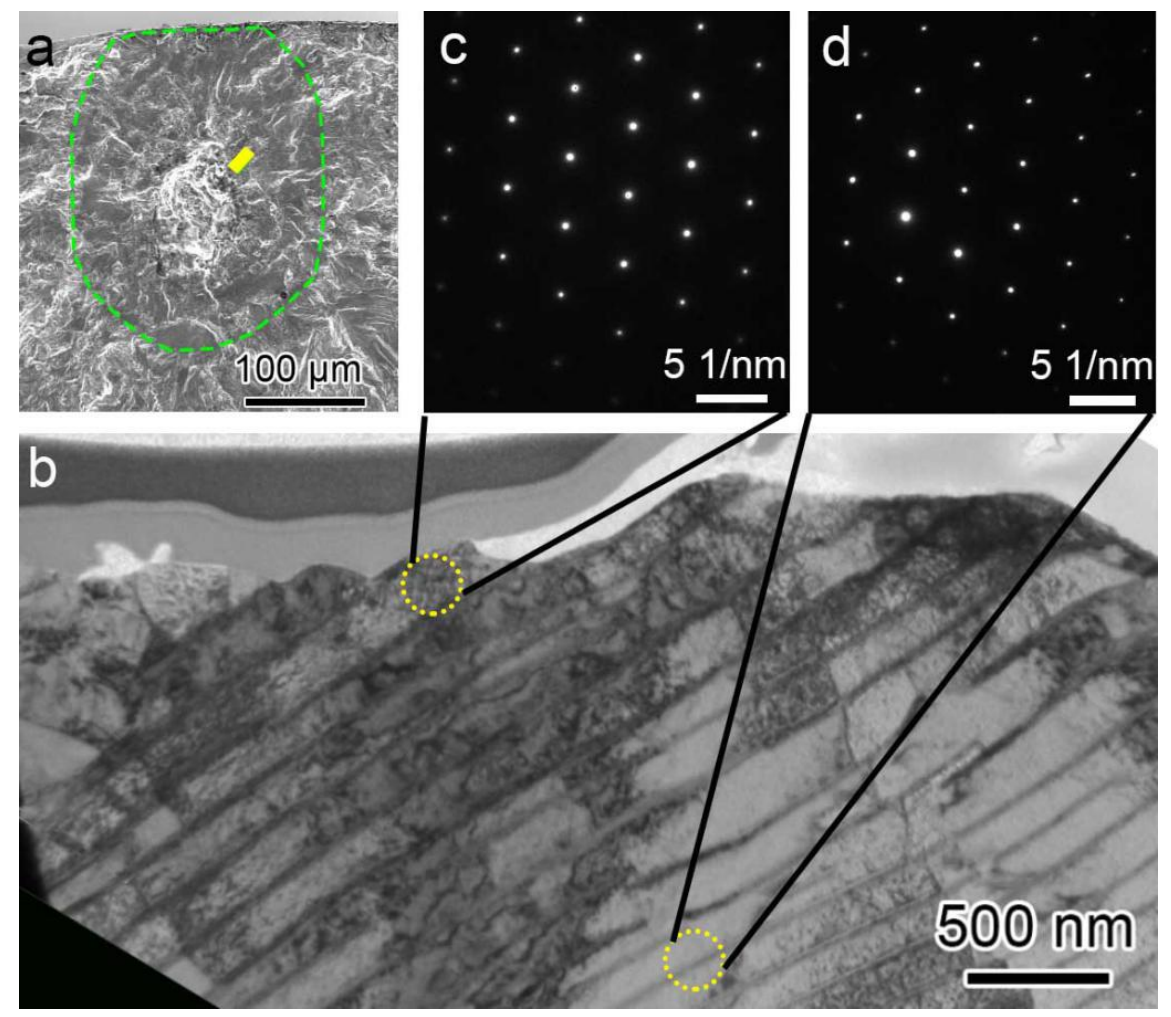

Fig. 7. Microstructure characterization of the crack initiation region for the case under axial loading: (a) fracture surface with location for TEM sample marked by the rectangle, (b) bright-field image, (c) SAED pattern at a location just under the crack initiation surface, and (d) SAED pattern at a location approximately $1.5 \mu \mathrm{m}$ away from the crack initiation surface.

Fig. 8a shows a TEM sample which contains the microstructure in the crack initiation region under rolling contact loading. The sample prepared with the FIB technique was observed by TEM, as shown in Fig. 8b. Three layers are delineated in the sample, i.e., a protective $\mathrm{Pt}$ coating layer $(\mathrm{Pt})$, a 50-500 nm nanograin layer (NG), and a pearlite layer (PL). Pt plays the role of protection; NG is a 50-500 $\mathrm{nm}$ thick nanograins; PL is the origin microstructure of pearlite. SAED was conducted on the NG and PL layers, as shown in Fig. 8c and d, respectively. For the NG layer, the SAED pattern in Fig. 8c is polycrystalline which shows discontinuous diffraction rings, suggesting that several grains existed within the diffraction area. For the PL layer, a pattern of isolated spots is shown in the SAED image (Fig. 8d), which indicates normal diffraction from a single grain. Therefore, we can infer that a layer of nanograins was formed from the pearlite. Away from this narrow layer, the microstructure had the features of pearlite. 


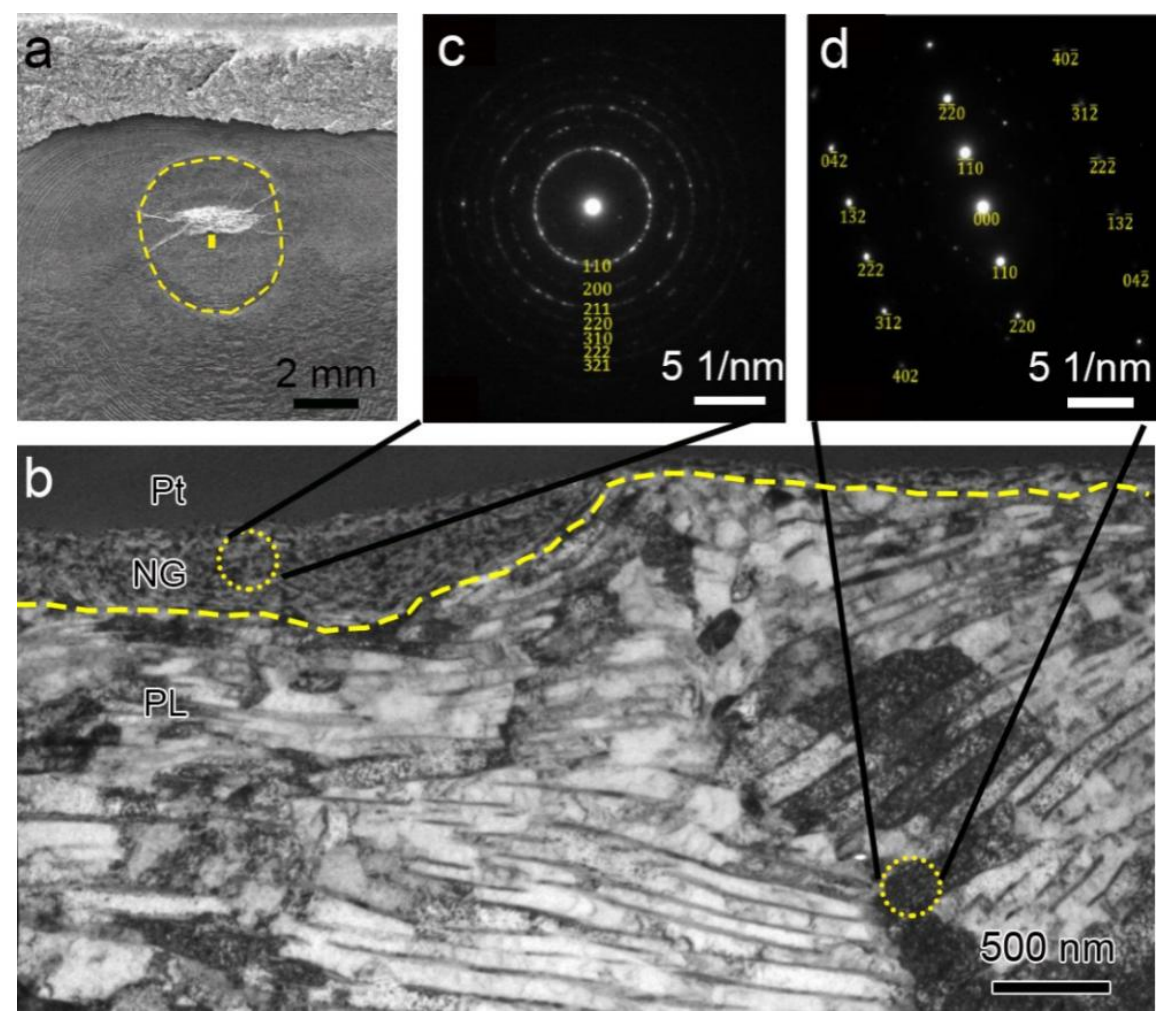

Fig. 8. SEM image, BFI and SAED patterns of crack initiation region for the case under rolling contact loading: (a) SEM image with the TEM sample location marked by the rectangle; (b) BFI of the microstructure in the FiE region. (c) SAED pattern under the FiE surface, and (d) SAED pattern away from the FiE surface.

We examined the cross-sectional structures of the samples in the FiEs during VHCF under axial loading (Fig. 9) and rolling contact loading (Fig. 10). Fig. 9a and Fig. 10a show the TEM sample position obtained by the FIB technique, which was far away from the inclusion and located in the middle of the FiE. The BFI results in Fig. 9b present the original pearlite, indicating that grain refinement did not occur in the whole FiE region, and isolated spots from a single grain were present both underneath and far away from the FiE surface (Fig. 9c and d). For the VHCF under axial loading, grain refinement did not occur in the crack initiation and early propagation regions. However, for the VHCF under rolling contact loading, only nanograins were observed, and the original pearlite disappeared completely, as shown in Fig. 10b, which was confirmed by the SAED results (Fig. 10c and d). These results indicated that grain refinement existed both underneath and far away from the FiE surface. For axial loading, no grain refinement occurred in the FiE. Thus, refinement occurred during VHCF under rolling contact loading. It is worth noting that microcracks were observed in the nanograins (marked by arrows in Fig. 10b). 


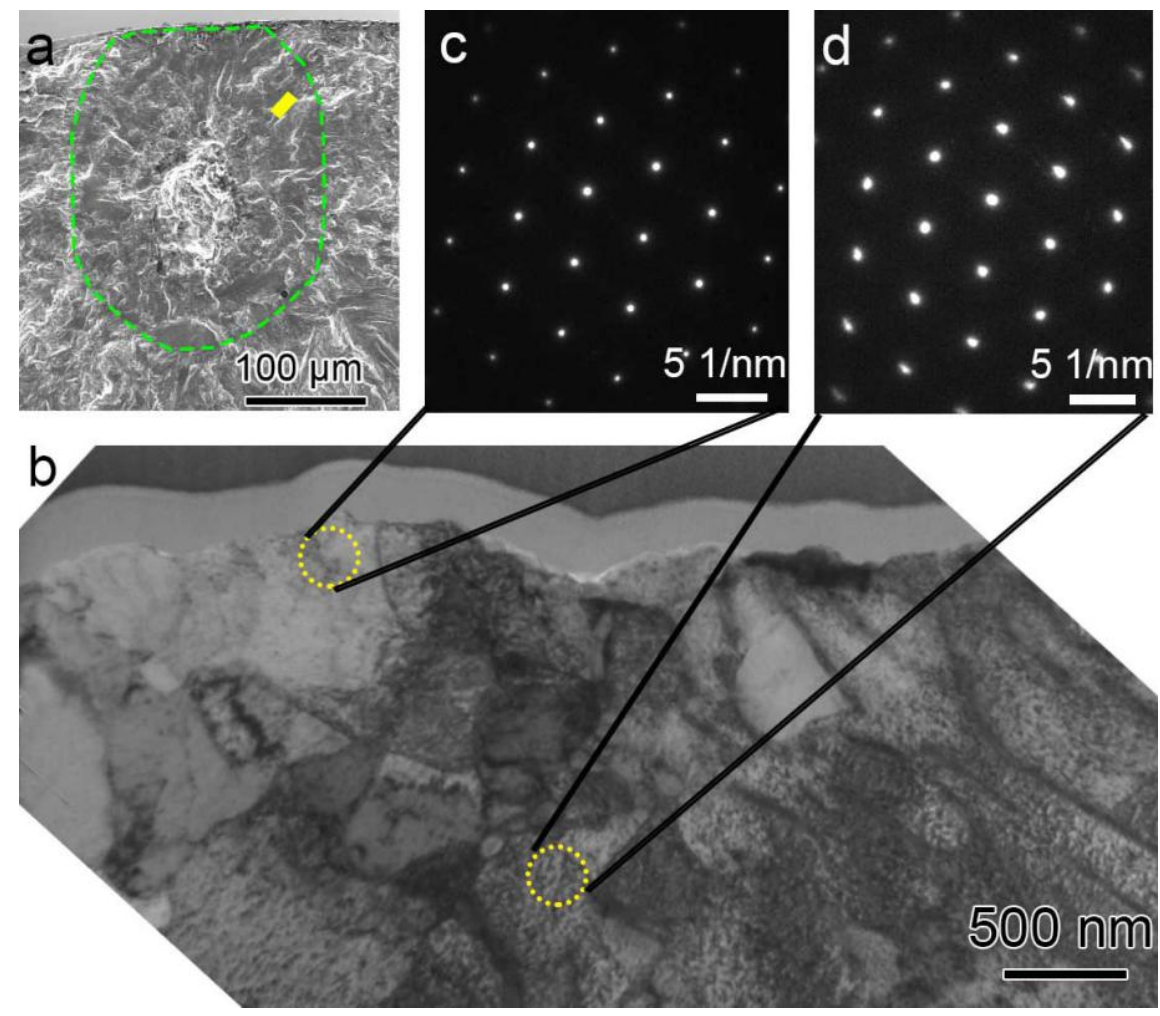

Fig. 9. BFI and associated SAED patterns of FiE for the case under axial loading: (a) TEM sample location marked by the yellow rectangle, (b) BFI of the microstructure underneath the FiE surface, (c) SAED pattern underneath the FiE surface, and (d) SAED pattern away from the FiE surface. 


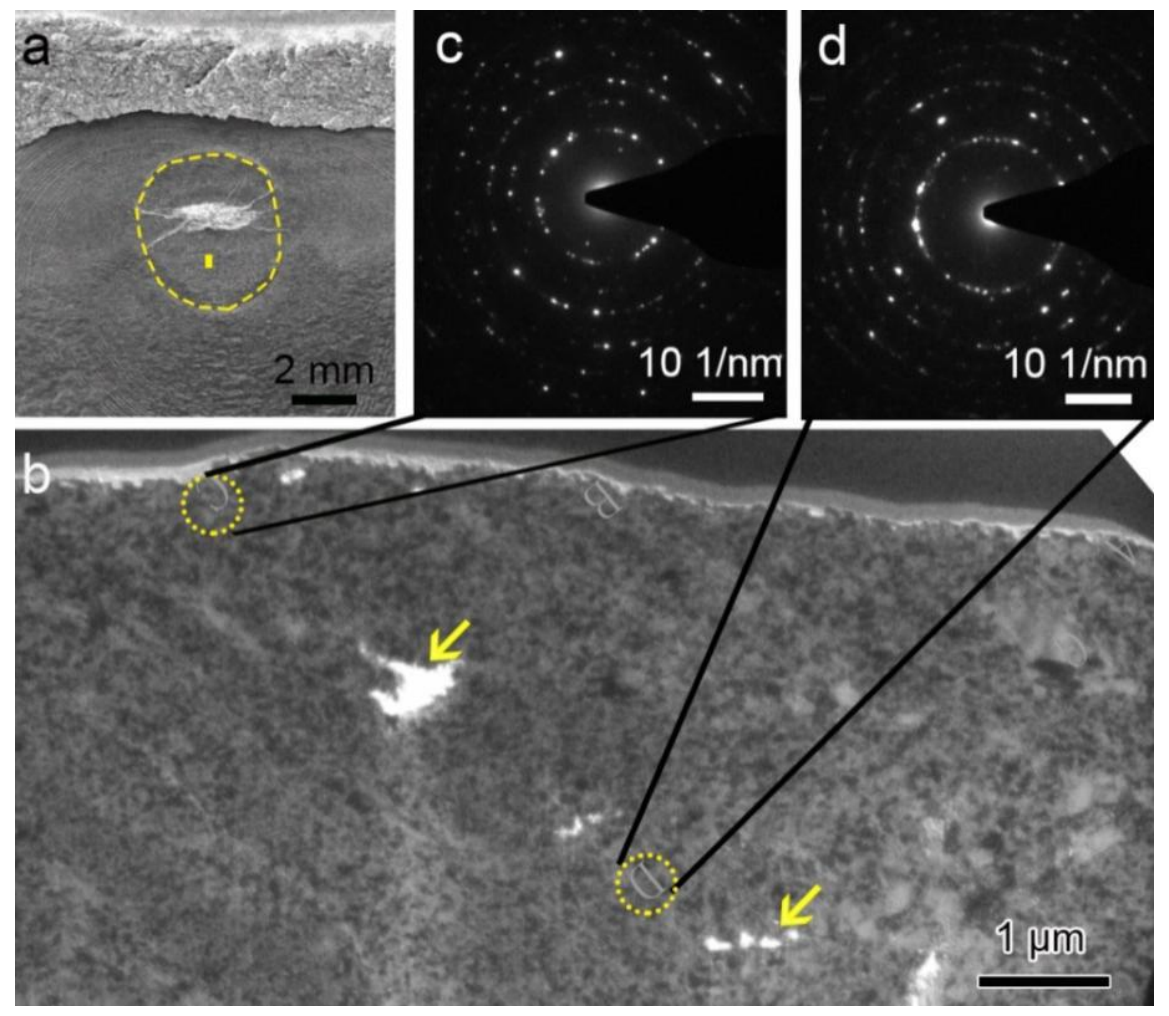

Fig. 10. BFI and associated SAED patterns of the FiE for the case under rolling contact loading: (a) TEM sample location marked by the yellow rectangle, (b) BFI of the microstructure underneath the FiE surface, (c) SAED pattern underneath the FiE surface, and (d) SAED pattern away from the FiE surface.

The microstructure of the FiE for the case of VHCF under rolling contact loading was characterized by TEM, as shown in Fig. 11. The TEM sample was prepared by the FIB technique, and the sample location is presented in Fig. 11a. The BFI results in Fig. 11b show nanograins in the whole sample, and microdamage marked by arrows also formed. The SAED results in Fig. 11c and d show discontinuous diffraction circles that are clearer than those in Fig. 7 and 9. It is interesting that nanograins formed even away from the FiE. 


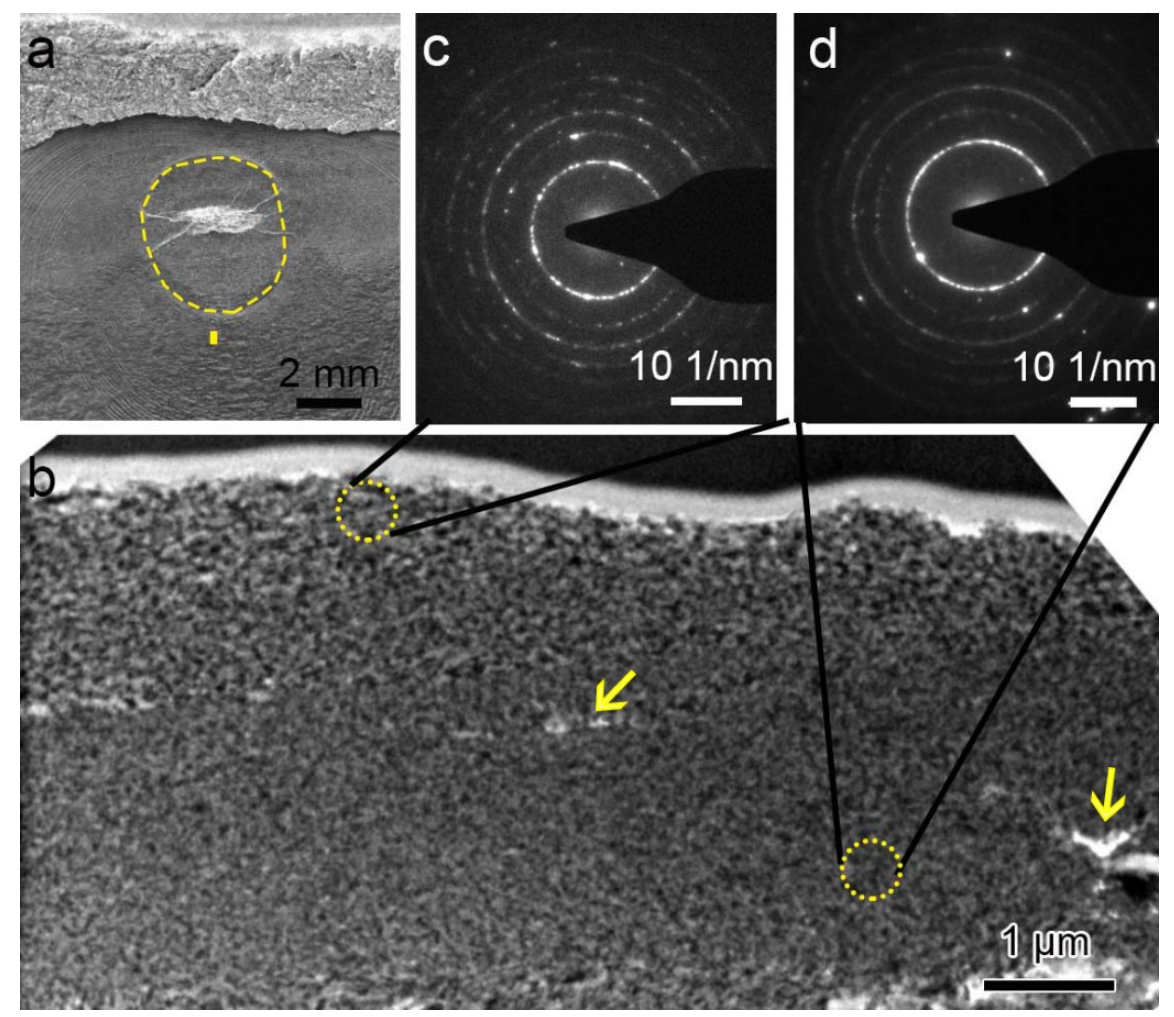

Fig. 11. SEM and TEM images of the extracted cross-section TEM samples out of the FiE region for the specimen that failed under rolling contact loading. (a) SEM image of the extracted cross-section locations by FIB, (b) BFI results of the extracted cross-section samples, and (c) and (d) SAED patterns underneath and away from the fracture surface, respectively.

Fig. 12a and b present a high-magnification BFI and corresponding dark-field image of the NG layer, showing nanograins in the NG layer with a distinct morphology in the crack initiation region under rolling contact loading. Subsequently, the grain sizes in the NG layer were measured from the BFIs. The result was based on the measurements of 517 grains. Fig. 12c shows the distribution of the nanograin sizes, indicating that the nanograin sizes range from 18 to $86 \mathrm{~nm}$ with an average value of $30 \mathrm{~nm}$. The diameter of the original pearlite is $8 \mu \mathrm{m}$ on average, and the average width of the lamellar ferrite in the pearlite is approximately 145 $\mathrm{nm}$. The microstructure evolution in this area is a grain refinement process with a scale from micrometers to nanometers. 
a

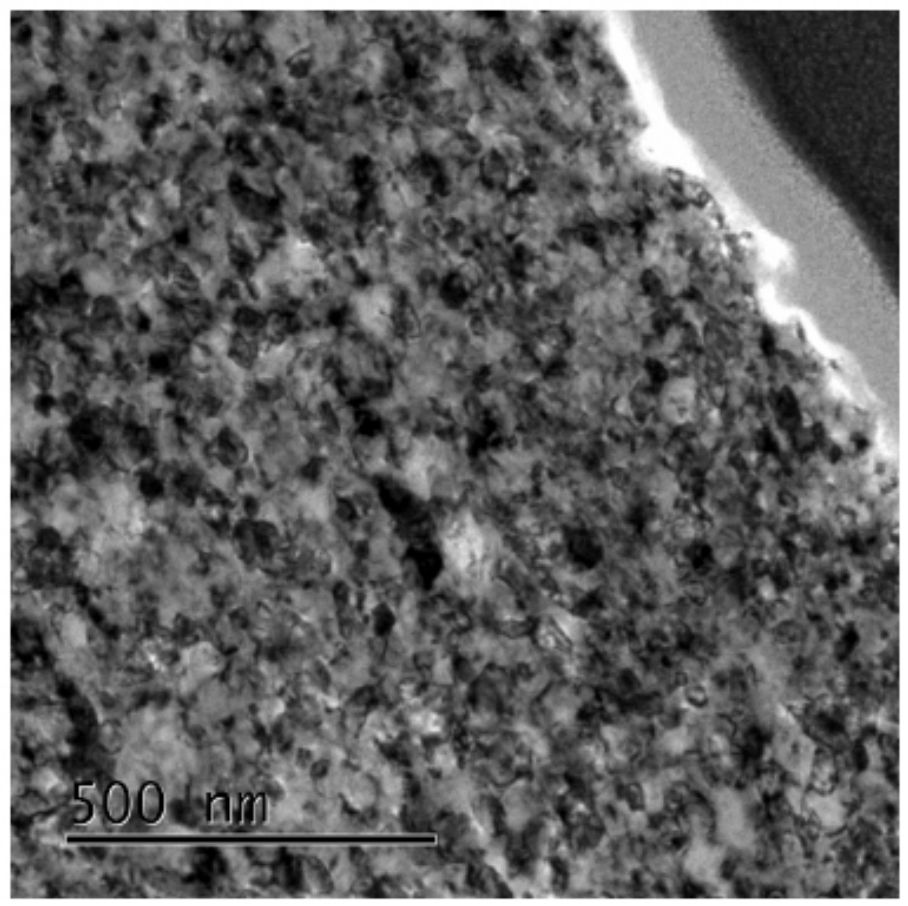

b
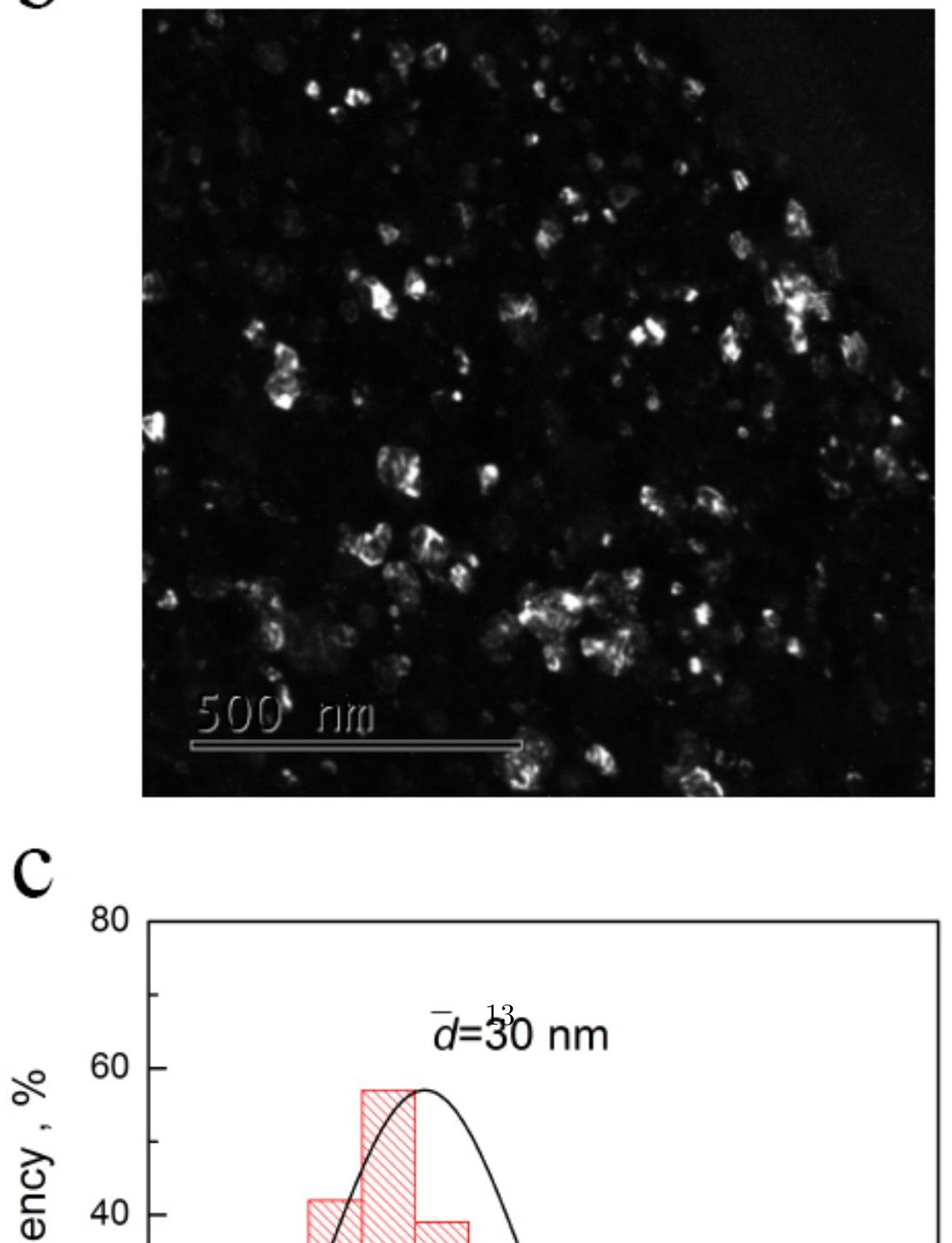
Fig. 12. High magnification images of the NG layer and the distribution of grain sizes in the NG layer. (a) BFI of the NG layer, (b) dark-field image of the NG layer, and (c) size distribution of the nanograins.

In summary, the ferrite nanograins form during VHCF under rolling contact loading, and disappear for the case of axial loading. Nanograins formation also occurred in the crack initiation region during VHCF in GCr15 and Ti-6Al-4V under axial loading at a negative stress ratio and disappeared at a positive stress ratio. According to the NCP model [17], nanograins formation is attributed to the numerous cyclic presses between the originated crack surfaces. Cyclic pressing between the crack surfaces occurred for both cases under axial loading and rolling contact loading. As shown in Fig. 13a, the axial compressive stress is approximately 300 $\mathrm{MPa}$, which is too small to form the nanograins. While the axial compressive stress is over $1 \mathrm{GPa}$, and the two shear stresses are also very large for the VHCF under rolling contact loading. Compared with VHCF with Mode I crack, the VHCF with mix Mode II-III crack will help the nanograins formation due to the shear plastic strain with a large compressive stress (Fig. 13b).
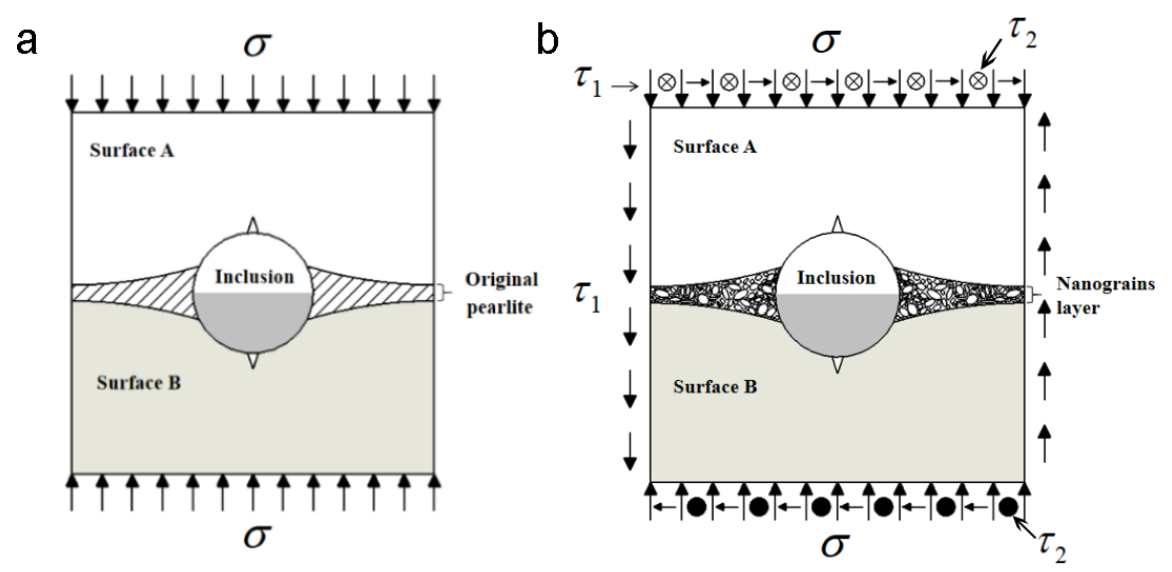

Fig. 13. Schematic of microstrucutre evolution on the fracture surface of VHCF under axial loading (a) and rolling contact loading (b), $\sigma$ : axial compressive stress, $\tau_{1}$ : shear stress for mode II crack, $\tau_{2}$ : shear stress for mode III crack.

\subsection{Mechanical properties of the nanograins layer}

The usefulness of nanoindentation measurements to obtain the fundamental mechanical properties of materials has been widely demonstrated in recent years. Here, we applied nanoindentation to test the mechanical properties of the nanograin layer (NG layer in Fig. 10 and Fig. 11) and matrix (pearlite layer in Fig. 8). Fig. 14 presents the load vs. depth indentation graphs for the NG layer and matrix. The hardness values of the NG layer and matrix up to a maximum load of $5 \mathrm{mN}$ are reported in Table 1 . With the same maximum load of $5 \mathrm{mN}$, the average nanoindentation depth of the NG layer was $796 \mathrm{~nm}$, which is larger than that of the matrix $(298 \mathrm{~nm}$ ). Moreover, the area (A in Table 2) of the nanoindentations for the NG layer was larger than that of the matrix. This was attributed to the hardness of the NG layer (0.61 GPa) being lower than that of the matrix $(2.78 \mathrm{GPa})$. 


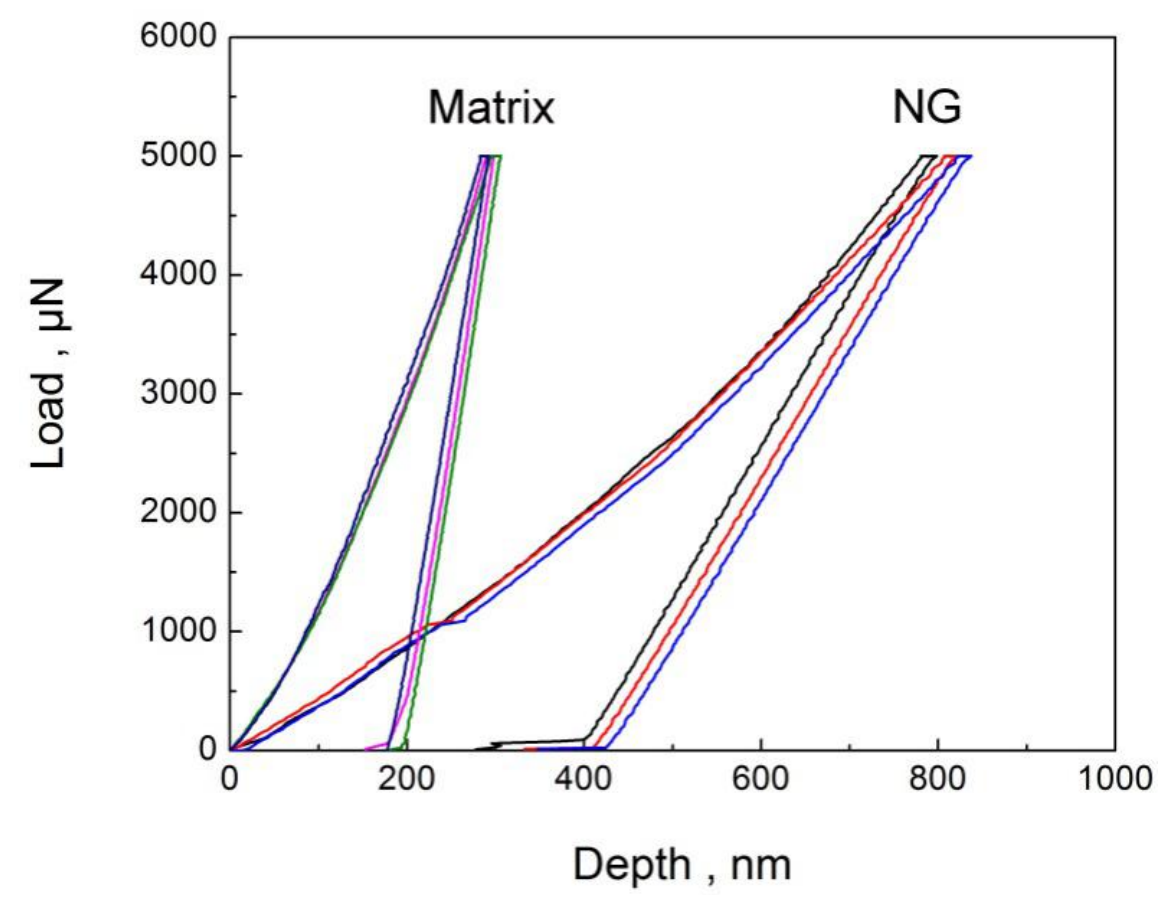

Fig. 14. Load vs. depth for the nanoindentation of the NG layer and the matrix.

\begin{tabular}{lllll}
\hline Name & $\mathrm{A}\left(\mathrm{nm}^{2}\right)$ & $\mathrm{h}_{\max }(\mathrm{nm})$ & $\mathrm{h}_{\text {eff }}(\mathrm{nm})$ & $\mathrm{H}(\mathrm{GPa})$ \\
\hline $\mathrm{N}-1$ & 1908489 & 306 & 305 & 2.62 \\
$\mathrm{~N}-2$ & 1664125 & 293 & 292 & 3.00 \\
$\mathrm{~N}-3$ & 1828385 & 299 & 297 & 2.73 \\
$\mathrm{M}-1$ & 8654722 & 822 & 815 & 0.58 \\
$\mathrm{M}-2$ & 8042376 & 798 & 790 & 0.62 \\
$\mathrm{M}-3$ & 7862642 & 791 & 783 & 0.64 \\
\hline
\end{tabular}

Table 1 Nanoidentation for the NG layer and the matrix

According to the Hall-Patch equation, the hardness of the nanograins is larger than that of coarse grains. However, Solano-Alvarez et al reported that the white-etching areas with nanograins that develop in carbidefree bainite are softer than the matrix [19]. Then, EPMA was used to test the distribution of carbon (C), silicon $(\mathrm{Si})$ and manganese $(\mathrm{Mn})$ in the nanograin layer and matrix. Fig. 15a and b shows the tested positions, which contain the nanograin layer and matrix. The contents of $\mathrm{C}, \mathrm{Si}$ and $\mathrm{Mn}$ are presented in Fig. $15 \mathrm{c}$ and $\mathrm{d}$. The contents of $\mathrm{C}$ in the matrix were higher than those in the NG layer, while the contents of Si and $\mathrm{Mn}$ in the NG layer and matrix were the same. The disappearance of $\mathrm{C}$ may be the reason that the NG layer was softer than the matrix. However, further investigation should be conducted to explain the unique results. 

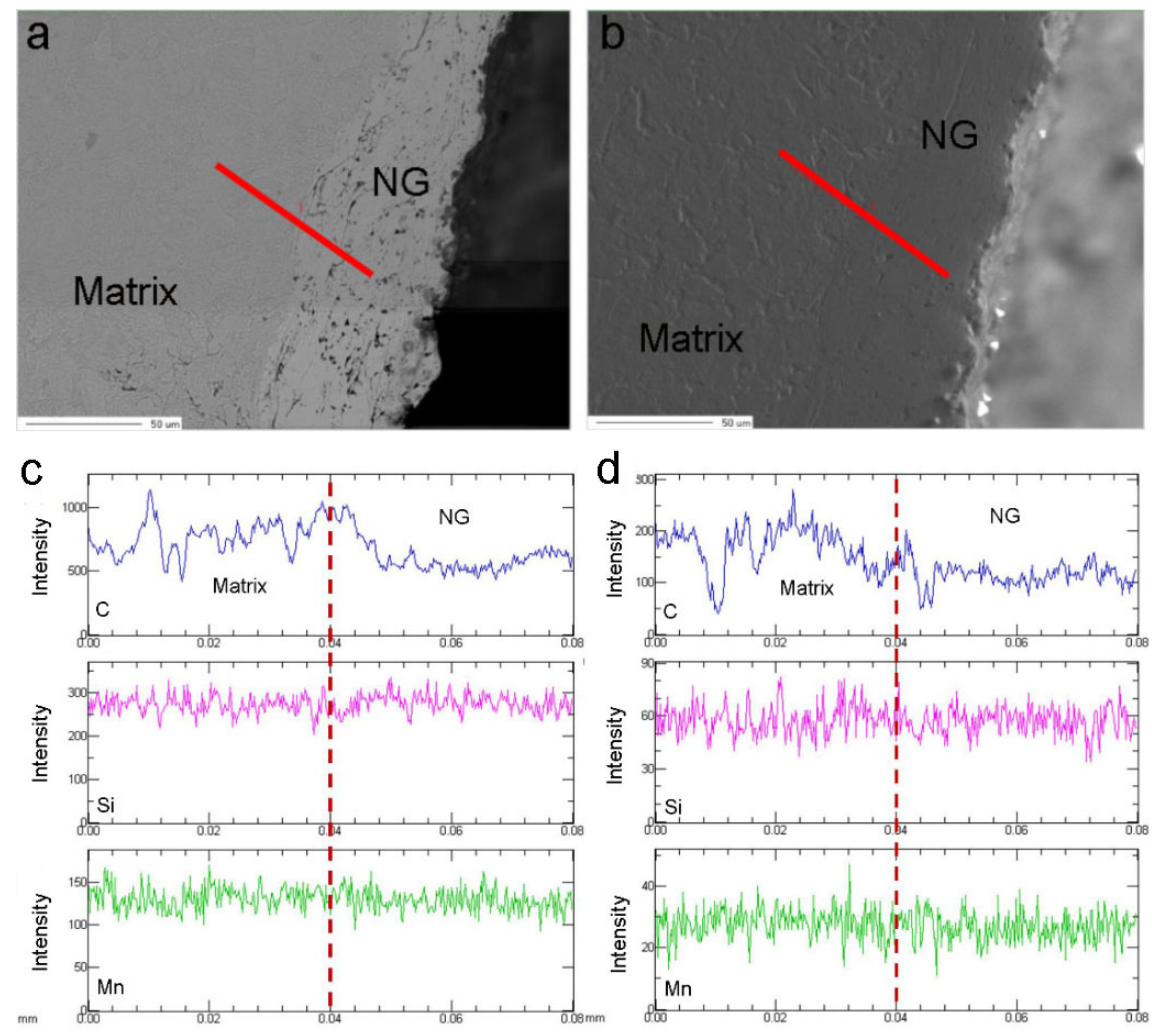

Fig. 15. Tested positions (marked by the red line) and results of the EPMA line scan analysis: (a) position 1, (b) position 2, line scan analysis results of (c) position 1 and (d) position 2.

\section{Conclusions}

This paper investigated the VHCF behavior of wheel steel under axial loading and rolling contact loading. The microstructure and mechanical properties of the crack initiation region were characterized. The following conclusions are drawn.

1. The wheel steel under axial loading presents a VHCF behavior with Mode I crack. Surface and interior crack initiation occurred with equal probability at both low and high stress levels and produced a dual linear S-N curve since the value of fatigue limits for the surface and interior crack initiation are close.

2. The VHCF under rolling contact loading is a VHCF behavior with mix Mode II-III crack. Cracks were initiated from the interior $\mathrm{Al}_{2} \mathrm{O}_{3}$ inclusion and the fatigue life was beyond $10^{7}$ cycles. Fatigue bands were observed on the fracture surface under rolling contact loading. FGA feature was not obvious.

3. The ferrite nanograins form during VHCF under rolling contact loading, and disappear for the case of axial loading. Compared with VHCF with Mode I crack, the VHCF with mix Mode II-III crack will help the nanograins formation due to the shear plastic strain with a large compressive stress. Meanwhile, the formed nanograins were softer than the matrix caused by the redistribution of the carbon.

\section{Author Contributions}

Xiaolong Liu: data analysis; conceptualization; methodology; writing-original draft, writing-review and editing. Pengcheng Gao: methodology; experiments conducting; data analysis. Si Wu: experiments conducting; data analysis; writing-review and editing. Guanzhen Zhang: methodology; data analysis; writing-review and editing. Tao Cong: conceptualization; methodology; writing-original draft; writing-review and editing. 


\section{Acknowledgments}

Financial support from the National Natural Science Foundation of China (No. 11802011), the Joint Funds of the National Natural Science Foundation of China (No. U1834202), the Science and Technology Research and Development Program of China State Railway Group Co., Ltd. (P2019J002) and the Fund of China Academy of Railway Sciences Corporation Limited (No. 2020YJ118) are acknowledged.

\section{References}

[1] S.X. Li, Effects of inclusions on very high cycle fatigue properties of high strength steels. Int Mater Rev 2012; 57: 92-114.

[2] M. Zimmermann, Diversity of damage evolution during cyclic loading at very high numbers of cycles. Int Mater Rev 2012; 57: 73-91.

[3] J. Campos, G. De Rus, Some stylized facts about high-speed rail: A review of HSR experiences around the world. Transport policy 2009; 16: 19-28.

[4] M. Givoni, Development and Impact of the Modern High-speed Train: A Review. Transport reviews 2006; 26: 593-611.

[5] A. Ekberg, E. Kabo, J.C.O. Nielsen, R. Lundén, Subsurface initiated rolling contact fatigue of railway wheels as generated by rail corrugation. Int J Solids Struct 2007; 44: 7975-7987.

[6] Y. Liu, L. Liu, S. Mahadevan, Analysis of subsurface crack propagation under rolling contact loading in railroad wheels using FEM. Eng Fract Mech 2007; 74: 2659-2674.

[7] P.J. Mutton, C.J. Epp, J. Dudek, Rolling contact fatigue in railway wheels under high axle loads. Wear 1991; 144: 139-152.

[8] A. Ekberg, B. Akesson, E. Kabo, Wheel/rail rolling contact fatigue - Probe, predict, prevent. Wear, 2014; 314: $2-12$.

[9] Tao Cong, Jianmin Han, Youshi Hong, Joseph Domblesky, Xiaolong Liu. Shattered rim and shelling of high-speed railway wheels in the very-high-cycle fatigue regime under rolling contact loading. Eng Fail Anal 2019; 97: 556-567.

[10] Guanzhen Zhang, Ruiming Ren. Study on typical failure forms and causes of high-speed railway wheels. Eng Fail Anal 2019; 105:1287-1295.

[11]Zhi Yong Huang, Han Qing Liu, Hao Min Wang, Danièle Wagner, Muhammad Kashif Khan, Qing Yuan Wang, Effect of stress ratio on VHCF behavior for a compressor blade titanium alloy. Int J Fatigue 2016; 93: 232-237.

[12] Zhi Yong Huang, Danièle Wagner, Claude Bathias, Paul C. Paris. Subsurface Crack Initiation and Propagation Mechanism in the Gigacycle Fatigue. Acta Materialia 2010; 58: 6046-6054

[13] W. Li, X. Xing, N.Gao, M. Li, R. Sun, S. Zhou, T. Sakai. Subsurface facets-induced crack nucleation behavior and microstructure-based strength evaluation of titanium alloys in ultra-long life regime. Mater Sci Eng A 2019: 138055.

[14] W. Li, H. Deng, Z. Sun, Z. Zhang, L. Lu, T. Sakai. Subsurface inclusion-induced crack nucleation and growth behaviors of high strength steels under very high cycle fatigue: Characterization and microstructurebased modeling. Mater Sci Eng A 2015; 641:10-20.

[15] MingLiang Zhu, Long Jin, FuZhen Xuan. Fatigue life and mechanistic modeling of interior micro-defect induced cracking in high cycle and very high cycle regimes. Acta Mater 2018; 157: 259-275.

[16] M.L. Zhu, F.Z. Xuan, Y.N. Du, S.T. Tu.Very high cycle fatigue behavior of a low strength welded joint at moderate temperature. Int J Fatigue 2012; 40: 74-83. 
[17] Y. Hong, X. Liu, Z. Lei, C. Sun. The formation mechanism of characteristic region at crack initiation for very-high-cycle fatigue of high-strength steels. Int J Fatigue 89 (2016) 108-118.

[18] Hang Su, Xiaolong Liu, Chengqi Sun, Youshi Hong. Nanograin layer formation at crack initiation region for very-high-cycle fatigue of a Ti-6Al-4V alloy. Fatigue Fract Eng Mater Struct 2017; 40: 979-993.

[19] W. Solano-Alvarez, E.J. Pickering, M.J. Peet, K.L. Moore, J. Jaiswal, A. Bevan, H.K.D.H. Bhadeshia. Soft novel form of white-etching matter and ductile failure of carbide-free bainitic steels under rolling contact stresses. Acta Mater 2016; 121: 215-226.

[20] P. Rycerz, A. Olver, A. Kadiric. Propagation of surface initiated rolling contact fatigue cracks in bearing steel. Int J Fatigue 2017; 97: 29-38.

[21] N.K. Arakere. Gigacycle Rolling Contact Fatigue of Bearing Steels: A Review. Int J Fatigue 2016; 93: 238-249.

[22] S. Averbeck, E. Kerscher. Influence of multiaxial fatigue loading conditions on white etching crack formation. Eng Fract Mech 2017; 174: 180-195.

[23] M.H. Evans. An updated review: white etching cracks (WECs) and axial cracks in wind turbine gearbox bearings. Mater Sci Tech 2016; 32: 1133-1169.

[24] H.K.D.H. Bhadeshia. Steels for bearings. Prog Mater Sci 2012; 57: 268-435.

[25] W. Solano-Alvarez, J. Duff, M.C. Smith, H.K.D.H. Bhadeshia. Elucidating white-etching matter through high-strain rate tensile testing. Mater Sci Tech 2017; 33: 307-310.

[26] M.H. Evans, A.D. Richardson, L. Wang, R.J.K. Wood. Serial sectioning investigation of butterfly and white etching crack (WEC) formation in wind turbine gearbox bearings. Wear 2013; 302: 1573-1582.

[27] H.K.D.H. Bhadeshia, W. Solano-Alvarez, Critical assessment 13: elimination of white etching matter in bearing steels, Mater Sci Tech 2015; 31: 1011-1015.

[28] M.H. Evans. An updated review: white etching cracks (WECs) and axial cracks in wind turbine gearbox bearings. Mater Sci Technol 2016; 32: 1133-1169.

[29] M.H. Evans, White structure flaking in wind turbine gearbox bearings: effects of 'butterflies' and white etching cracks. Mater Sci Tech 2012; 28: 3-22.

[30] R. Osterlund, O. Vingsbo, L. Vincent, P. Guiraldenq. Butterflies in fatigued ball bearings - formation mechanisms and structure. Scand J Metall 1982; 11: 23-32.

[31] A. Grabulov, R. Petrov, H.W. Zandbergen. EBSD investigation of the crack initiation and TEM/FIB analyses of the microstructural changes around the cracks formed under Rolling Contact Fatigue (RCF). Int J Fatigue, 2010; 32: 576-583.

[32] A. Grabulov, U. Ziese, H.W. Zandbergen. TEM/SEM investigation of microstructural changes within the white etching area under rolling contact fatigue and 3-D crack reconstruction by focused ion beam. Scr Mater 2007; 57: 635-638. 